\title{
QUEM SOMOS! O debate sobre o conceito de pessoa e o início da vida
}

\section{Who we are! The debate over the concept of person and the beginning of live}

\section{Karen Bergesch}

Doutora em Teologia pela Ludwig Maximillian Universität München e pela Escola Superior de Teologia, professora de Filosofia no Serviço Nacional de Aprendizagem Industrial (SENAI) de Brusque, professora de Filosofia na Fundação Universidade Regional de Blumenau (FURB), Santa Catarina, SC - Brasil, e-mail: karenbergesch@hotmail.com

\section{Resumo}

O presente artigo reflete sobre o tema do início da vida e o conceito de pessoa. Para se definir o início da vida é necessário compreender quem é a pessoa, visto que a vida humana não começa com a formação de um novo indivíduo, mas se mantém através dele. Ao debate pertencem a compreensão de autonomia, dignidade e materialidade humana, pois a existência humana e as possibilidades de pesquisa com embriões ocorrem através da corporeidade. O encontro interdisciplinar pode enriquecer o debate, apresentando perspectivas diferentes sobre a compreensão da vida e os cuidados necessários frente à fragilidade humana. A multiplicidade característica da pós-modernidade é desafiada quando decisões precisam ser realizadas. Por isso, tão 
importante quanto o resultado final é o processo de amadurecimento das questões colocadas.

Palavras-chave: Vida humana. Conceito de pessoa. Autonomia. Dignidade. Corporeidade.

\section{Abstract}

The following article takes as an issue the beginning of life and the concept of person. To answer when the life begins, it is necessary to understand who is the person, because the human life does not begin in each new human being, but continues through each new life. The concepts of autonomy, dignity and human materiality integrate the debate, because human existence and possibilities of research with embryos take place in corporeity. Interdisciplinarity can guide the debate presenting different perspectives about life and the necessary care up against human fragility. The multiplicity of concepts in post-modernity is defied when decisions must be made. So, as important as any decision in research is the debate process.

Keywords: Human life. Concept of person. Autonomy. Dignity. Corporeity.

\section{INTRODUÇÃO}

A definição sobre o início da vida apresenta-se como um desafio para a compreensão humana em diferentes áreas do saber. A grande dificuldade ocorre porque a vida está em constante transformação e movimento, organizando-se através de ciclos interligados. Isso significa que não há um momento estático, pontual, para se definir tanto o início da vida quanto o seu fim. Tudo é processo.

Sob esse enfoque torna-se fundamental definir o conceito de pessoa, pois é esse conceito que vai guiar a ação humana em diversas áreas do saber na 
relação e cuidados com os seus semelhantes. O presente artigo reflete a questão do início da vida humana sob a perspectiva do conceito de pessoa. Para tanto, apresenta brevemente as diversas possibilidades de compreensão do início da vida na biologia para, então, voltar-se ao debate filosófico-teológico.

\section{A biologia e suas possíveis compreensões do início da vida humana}

A rigor, como afirma José Roberto Goldim,

a vida humana não começa a cada reprodução, ela continua, pois o fenômeno vital se mantém, não é nem extinto nem restabelecido, prossegue. A vida de um novo indivíduo é que tem início. O estabelecimento de critérios biológicos - início da vida de um ser humano - ou filosóficos - início da vida de uma pessoa - ou ainda, legais é uma discussão difícil, mas por isso mesmo desafiadora (GOLDIM, 2009a, p. 1).

Há mais de uma definição possível para o início da vida humana. Ainda conforme Goldim, existem quatro linhas de pensamento principais. A primeira afirma que a vida começa com a fertilização do óvulo pelo espermatozoide. A segunda teoria defende que o indivíduo surge na terceira semana de gestação, quando o embrião não pode mais se dividir e o novo conjunto genético assume o controle da nova célula.

A terceira teoria é que a vida humana começa com o desenvolvimento do cérebro na oitava semana. E a quarta afirma que a vida começa a partir da $24^{\mathrm{a}}$ semana de gestação, pois nesse período os pulmões estão formados e o feto já possui condições de sobreviver fora da barriga da mãe (GOLDIM, 2009b, p. 1). Cada uma dessas teorias são formas diferentes de se compreender a vida humana e, por isso mesmo, defendidas por grupos diversos que possuem seus próprios interesses discursivos e éticos.

Goldim (2009a, p. 1) apresenta 20 possibilidades de se compreender o início da vida a partir de diferentes critérios, conforme a Tabela 1. 
BERGESCH, K.

Tabela 1 - O início da vida segundo diferentes critérios

\begin{tabular}{|c|c|c|}
\hline Tempo decorrido & Característica & Critério \\
\hline $0 \mathrm{~min}$ & $\begin{array}{l}\text { Fecundação } \\
\text { fusão de gametas }\end{array}$ & Celular \\
\hline 12 a 24 horas & $\begin{array}{l}\text { Fecundação fusão } \\
\text { dos pró-núcleos }\end{array}$ & Genotípico estrutural \\
\hline $\begin{array}{l}2 \text { dias } \\
3 \text { a } 6 \text { dias }\end{array}$ & $\begin{array}{l}\text { Primeira divisão celular } \\
\text { Expressão do novo } \\
\text { genótipo }\end{array}$ & $\begin{array}{l}\text { Divisional } \\
\text { Genotípico funcional }\end{array}$ \\
\hline 6 a 7 dias & Implantação uterina & Suporte materno \\
\hline 14 dias & $\begin{array}{l}\text { Células do indivíduo } \\
\text { diferenciadas das células } \\
\text { dos anexos }\end{array}$ & Individualização \\
\hline 20 dias & Notocorda maciça & Neural \\
\hline 3 a 4 semanas & $\begin{array}{l}\text { Início dos batimentos } \\
\text { cardíacos }\end{array}$ & Cardíaco \\
\hline 6 semanas & $\begin{array}{l}\text { Aparência humana e } \\
\text { rudimento de todos } \\
\text { os órgãos }\end{array}$ & Fenotípico \\
\hline 7 semanas & $\begin{array}{l}\text { Respostas reflexas à } \\
\text { dor e à pressão }\end{array}$ & Sensciência \\
\hline 8 semanas & $\begin{array}{l}\text { Registro de ondas } \\
\text { eletroencefalográficas } \\
\text { (tronco cerebral) }\end{array}$ & Encefálico \\
\hline $\begin{array}{l}10 \text { semanas } \\
12 \text { semanas } \\
12 \text { a } 16 \text { semanas }\end{array}$ & $\begin{array}{l}\text { Movimentos espontâneos } \\
\text { Estrutura cerebral completa } \\
\text { Movimentos do feto } \\
\text { percebidos pela mãe }\end{array}$ & $\begin{array}{l}\text { Atividade } \\
\text { Neocortical } \\
\text { Animação }\end{array}$ \\
\hline 20 semanas & $\begin{array}{l}\text { Probabilidade de } 10 \% \\
\text { para sobrevida fora do útero }\end{array}$ & Viabilidade extra-uterina \\
\hline 24 a 28 semanas & Viabilidade pulmonar & Respiratório \\
\hline 28 semanas & Padrão sono-vigília & Autoconsciência \\
\hline 28 a 30 semanas & Reabertura dos olhos & Perceptivo visual \\
\hline 40 semanas & $\begin{array}{l}\text { Gestação a termo ou } \\
\text { parto em outro período }\end{array}$ & Nascimento \\
\hline 2 anos após o nascimento & "Ser moral" & $\begin{array}{l}\text { Linguagem para } \\
\text { comunicar vontades }\end{array}$ \\
\hline
\end{tabular}

Rev. Pistis Prax., Teol. Pastor., Curitiba, v. 2, n. 1, p. 77-95, jan./jun. 2010 
Nessa tabela, observa-se que o último critério é a utilização da linguagem, que inicia aos 2 anos de idade. Esse critério ancora-se na característica do "ser moral". O "ser moral" seria aquele que possui condições de comunicar as suas vontades e desejos. Compreende-se, dessa forma, que a vida humana somente teria seu início nesse momento. $\mathrm{O}$ critério foi criticado por poder ser interpretado como defensor do infanticídio.

O debate sobre o critério para definição do início da vida humana assume importância, na sociedade hodierna, devido a dois aspectos. Primeiramente, a preocupação com a interrupção da gestação e, segundo, com as possibilidades de pesquisas com o embrião. A situação resulta do desenvolvimento da tecnologia médica. Diante da nova realidade de investigação médico-científica, surgem perguntas e debates voltados aos valores e posturas éticas que orientam tais pesquisas.

Sob esse aspecto, a sociedade hodierna encontrasse em um impasse, pois, por um lado, existe a possibilidade de pesquisar a cura para algumas doenças e, por outro, pergunta-se até que medida isso estaria correto e seria bom. A dúvida muitas vezes coloca a sociedade, cientistas e demais pesquisadores em uma situação de impasse. Para onde ir? Quem pode nos guiar em um mundo secularizado e pós-moderno? Será possível encontrar um único critério para a orientação de todos? A fim de encontrar soluções, o essencial encontra-se no diálogo, pois ele orienta o amadurecimento da questão.

\section{O encontro entre ciência, filosofia e teologia: um extrato do debate atual}

O debate relacionado ao início da vida humana envolve a compreensão de ser humano, pessoa, dignidade e autonomia. Conforme as definições atribuídas a esses conceitos, as possibilidades de investigação científicas, bem como as relações humanas, podem seguir diferentes rumos. O debate atual sobre a questão colocada pode ser apresentado didaticamente em dois pontos: a capacidade de raciocínio e o corpo.

\section{A capacidade de raciocínio $X$ a busca por dignidade}

O debate atual sobre o conceito de pessoa divide-se entre o enfoque da autonomia e o da dignidade humana. A razão ou capacidade de raciocínio é 
considerada característica própria da espécie homo sapiens sapiens. Portanto, ao caracterizar-se pessoa, esse aspecto está sempre presente. A capacidade de raciocínio confere autonomia e liberdade (Kant) que impulsionam o agir através de virtudes (Aristóteles) ou princípios (Principialismo), voltados para a relação com o grupo social e o meio ambiente (Contratualismo).

A capacidade de raciocínio marca a diferença entre os seres humanos que possuem deficiência mental e aqueles que não possuem. Essa diferença, na bioética, resulta em uma proteção especial para portadores de deficiência mental. Portanto, o objetivo é evitar abusos e proteger aqueles que não possuem a capacidade de exercer plenamente sua autonomia e liberdade (deficientes mentais e menores de idade).

Peter Singer, filósofo utilitarista, reflete sobre a autonomia até suas últimas consequências, fato que resulta em polêmica. Ele apresenta um conceito de pessoa baseado na exclusão. Membros da espécie homo sapiens sapiens que não possuem capacidade de raciocínio e autoconsciência (bebês até dois anos de idade e adultos que perdem essa capacidade devido a alguma doença degenerativa, como Alzheimer, por exemplo) deixam de ser pessoa. O conceito de Singer, portanto, permite flexibilidade para o ser ou não ser pessoa.

A intenção do filósofo é questionar a relação entre as espécies, quando o ser humano explora economicamente outras espécies de animais, como, por exemplo, em fazendas industriais ou na pesquisa científica. Singer propõe uma nova argumentação baseada no igual interesse em não sentir dor aplicada a todas as espécies. Esse interesse poderia ser o critério, segundo o filósofo, para a relação entre as diferentes espécies animais.

De acordo com Singer (2002a), a pessoa é caracterizada pela sua racionalidade e autoconsciência. O filósofo chega a esse conceito sucinto por meio de Joseph Fletcher e John Locke. Fletcher, teólogo protestante, descreve a pessoa como um ser com "consciência de si, autocontrole, senso de futuro e passado, capacidade de relacionar-se com outros, preocupação com outros, comunicação e curiosidade" (SINGER, 2002a, p. 96).

Locke "define uma pessoa como um ser inteligente e racional, dotado de razão e de reflexão, capaz de cogitar de si mesmo como uma mesma coisa pensante, em diferentes tempos e lugares" (SINGER, 2002a, p. 165). A semelhança da caracterização do conceito de pessoa entre Fletcher e Locke é grande. Assim, Singer opta pelo que ele considera o núcleo do conceito, racionalidade e autoconsciência, pois compreende que as outras características decorrem dessas. 
O termo humano possui um sentido biológico que é definido pela espécie. Ser humano é todo aquele indivíduo que pertence à espécie homo sapiens sapiens, o que pode ser verificado através de exames médicos. Assim, de acordo com Singer, os conceitos de pessoa e o de ser humano devem ser compreendidos separadamente e não como sinônimos, pois isso é um erro.

O embrião, o feto, a criança com profundas deficiências mentais e o próprio bebê recém-nascido são todos membros inquestionáveis da espécie Homo sapiens sapiens, mas nenhum deles é autoconsciente, têm senso de futuro ou capacidade de se relacionar com outros (SINGER, 2002b, p. 96).

Então, quem não possui a capacidade de elaborar um pensamento racional ou não possui autoconsciência não é considerado pessoa.

Essa distinção conceitual acarreta uma série de consequências na esfera jurídica e na pesquisa médico-científica de hoje. A eutanásia poderia ser praticada/ aplicada em pacientes terminais sem o fato ser considerado um problema moral, pois esses indivíduos pertenceriam à espécie homo sapiens sapiens, mas não seriam mais considerados pessoas. A pesquisa com embriões também não conduziria a questões morais, pois se trata de membros da espécie e não de pessoas.

A distinção entre os conceitos acima citados permite uma movimentação conceitual do indivíduo: primeiramente enquanto pessoa pertencente a uma espécie; segundo, como membro da espécie. A movimentação se dá principalmente no início e fim da vida. Até dois anos, o indivíduo não pode ser considerado pessoa por não preencher as características necessárias. No fim da vida, muitos indivíduos perdem seu status por desenvolverem algum tipo de doença degenerativa, como Alzheimer, por exemplo.

A questão que envolve toda a discussão e distinção conceitual entre pessoa e membro da espécie homo sapiens sapiens é a permissão para tirar a vida humana. Singer formula essa problemática através da pergunta "o que há errado em matar?", título de um artigo publicado em mais de um de seus livros. Ao apoiar a pesquisa com embriões e o aborto, por exemplo, o filósofo não reconhece como problema moral matar um embrião. Isso entra em confronto direto com a compreensão de sacralidade da vida.

O conflito surge no âmbito cristão que considera a vida sagrada. Singer apresenta duas observações quanto à afirmação "vida sagrada". Primeiramente, ela na verdade se refere à vida humana e não à vida de forma geral, pois o tratamento 
despendido aos seres humanos é totalmente diferente do despendido aos outros animais, como, por exemplo, os criados em fazendas industriais para fins de consumo humano. Segundo, a doutrina cristã não é mais de aceitação geral, apesar de sua influência permanecer na base da reflexão ética da singularidade e dos privilégios especiais da espécie humana (SINGER, 2002b, p. 99).

A proposta de Singer, então, é encontrar uma base ética que sirva à reflexão contemporânea da pluralidade. A base seria, segundo o filósofo, as sensações corporais de prazer e dor. Portanto, o fundamento ético partiria do corpo e suas sensações, pois essas independem do grau de consciência de si mesmo o que possibilita incluir os animais não humanos no mesmo critério. Esse argumento parece ser facilmente compreensível num primeiro momento, pois dor e prazer são sensações que todos já vivenciaram, mesmo que em proporções diferentes.

No entanto, num segundo momento, quando o filósofo aprofunda a reflexão, admite que é difícil o ser humano colocar-se na existência de outra espécie, pois se assim fosse haveria apenas um troca de papéis, o que impossibilitaria uma verdadeira compreensão de interesses, prazer e dor. Mesmo diante da dificuldade, Singer afirma que não é necessário organizar uma hierarquia de valor para vidas diferentes. Singer aposta na solução da questão através da investigação das preferências. Mas admite, no entanto, que até o momento o esclarecimento da questão permanece em aberto (SINGER, 2002b, p. 118).

As críticas dirigidas a Singer são muitas. Segundo Düwell (2003), essas podem ser divididas em dois blocos: A) questiona-se o princípio do interesse comum das espécies quanto à sua universalização, visto que a argumentação do filósofo é considerada fraca; B) não está claro porque foi escolhido o tema do evitar sentir dor como motivação do princípio. A crítica apresentada pela ética tradicional discutirá sempre a questão da "santidade da vida", que hoje é atualizada através do tema da "dignidade humana", na qual o ser humano é conceituado como imagem e semelhança de Deus.

A proposta de Singer não deve ser rapidamente refutada. Ela deve ser analisada com mais cuidado, pois se a pesquisa com embriões é hoje determinante para a descoberta da cura de doenças e realmente obtiver sucesso, então as descobertas científicas podem trazer grandes benefícios para a humanidade. Caso as descobertas realizadas na pesquisa com embriões sejam determinantes para a cura de doenças, os laboratórios e países que investiram na pesquisa poderão também comercializar medicamentos. Que tipo de exploração seria mantida? Que consequências haveria para a pessoa? 
A diferenciação entre pessoa e ser humano, proposta por Singer, bem como seu questionamento da relação entre as diferentes espécies de animais integram a discussão sobre dignidade humana. A dignidade humana é protagonista de discursos antagônicos em torno da pessoa. É o caso, por exemplo, da eutanásia. Em defesa da dignidade humana, há pessoas que apoiam a eutanásia e outras que a rechaçam. Assim, pergunta-se se a dignidade humana tornou-se uma ideologia, uma categoria de proteção ou de exclusão (AMMICHT-QUINN; JUNKER-KENNY; TAMEZ, 2003a, p. 6(166)).

Depois das denúncias dos crimes de guerra e após pesquisas científicas realizadas nos EUA na metade do século XX, surgiram várias declarações internacionais defendendo a dignidade humana. A dignidade tornou-se o valor dos valores. Segundo Patrick Verspieren (2003), apesar do forte discurso, a autonomia passou a receber destaque no debate bioético nos EUA. O peso recai sobre a liberdade de cada um realizar escolhas sobre os cuidados de seu corpo, tanto em tratamentos quanto em pesquisas médicas. Assim, o valor inerente à pessoa humana é colocado em um segundo plano. O deslocamento do discurso em prol da dignidade humana para o da autonomia não ocorre na Europa.

Os europeus mantêm em seus documentos sobre a Convenção dos Direitos Humanos e a Biomedicina o termo "dignidade". "O termo dignidade também é central na Declaração Universal sobre o Genoma Humano e os Direitos Humanos, adotada em 1997 pela Unesco, depois pela Assembléia geral da ONU. A influência da Europa foi determinante na redação do texto" (VERSPIEREN, 2003 , p. 15 (175)). Os europeus sustentam que não é possível apenas agir com o consentimento dos sujeitos em questões biomédicas. "Tornou-se evidente que era necessário interrogar-se sobre a compatibilidade entre tais manipulações e o respeito devido ao ser humano, e sobre os limites a fixar para a expansão das tecnologias biológicas" (VERSPIEREN, 2003, p. 15 (175)). O receio não se relaciona apenas ao indivíduo, mas se volta para a preservação da espécie humana.

Percebe-se, dessa forma, que há uma tensão entre Europa e EUA na definição de termos sobre o cuidado e a proteção da pessoa. A autonomia voltase mais para o indivíduo e remete à liberdade de ação. A dignidade torna-se o valor máximo da espécie humana enquanto grupo social. A tentativa de substituir um pelo outro pode ter sua origem na compreensão atual de dignidade, que, por sua vez, apresenta dificuldades de compreensão.

Segundo Regina Ammicht-Quinn (2003b), a dificuldade se encontra, por um lado, na apresentação do termo "dignidade" como um discurso vago 
em torno de conceitos como o verdadeiro, o belo, o bom. Por outro lado, sua fundamentação teológica se torna problemática em ambientes secularizados. Ammicht-Quinn pergunta: "Como apelar a uma dignidade que nos foi dada por Deus, quando o próprio 'Deus' é questionado?” (AMMICHT-QUINN, 2003 b, p. 32 (192)). No entanto, mesmo que o fundamento teológico seja questionado, a pergunta pela dignidade humana permanece.

O núcleo do debate não deve estar de forma alguma vazio. A autora relaciona questões de dignidade com o debate em torno da imagem do ser humano. Cada época histórica apresenta uma imagem do ser humano, questionando a anterior. Por exemplo, no século XX do Ocidente o modelo normativo de ser humano é o do sexo masculino. Portanto, o outro será o outro sexo, e as questões relacionadas à estrutura familiar, oportunidades de formação e trabalho para as mulheres passam a marcar o novo discurso.

A autora pergunta-se sobre a dignidade e imagem do ser humano diante da esfera da biomedicina. A mudança antropológica ocorre a partir do desenvolvimento da tecnologia que hoje é aplicada à medicina a partir da preocupação com o que pode ser produzido, o que pode ser consertado e o que pode ser controlado. Assim, a

imagem normativa do ser humano que vigorou até hoje - "o ser humano" é um ser vivo, gerado por um homem e uma mulher, nascido de uma mulher, que começa a envelhecer a partir do primeiro suspiro e que morre com a última batida do coração - é radicalmente questionada (AMMICHT-QUINN, 2003b, p. 32(192)).

A preocupação científica do momento parece estar voltada para a imagem do ser humano perfeito, que funcione de forma previsível, como uma máquina. Predomina, portanto, um discurso restritivo, que nega a dignidade a determinadas formas de vida humana. Então, o que é afinal de contas a dignidade? Joaquim Clotet constata que a dignidade teve concepções diferentes ao longo da história da filosofia moral ou da ética.

De Hipócrates (eusjemosúne), até Immanuel Kant (Würde), através de Cícero (decorum), Santo Tomás de Aquino (honestum, decorum) e João Pico della Mirandola (dignitas). Trata-se de uma noção difícil de definir com precisão, mas apresenta-se como um dos poucos valores universais e comuns da sociedade pluralista contemporânea (CLOTET, 2003, p. 212).

Rev. Pistis Prax., Teol. Pastor., Curitiba, v. 2, n. 1, p. 77-95, jan./jun. 2010 
Apesar da dificuldade em definir o termo, o conceito continua sendo trabalhado por autores contemporâneos. Paul Valadier apresenta a seguinte definição a partir da parábola do bom samaritano (Lc 10, v. 25 a 37):

A dignidade não é portanto um atributo próprio à pessoa em sua singularidade; ela é uma relação ou, melhor, ela se manifesta no gesto pelo qual nós nos referimos ao outro por considerá-lo ser humano, igualmente ser humano, mesmo se sua aparência denuncia uma não-humanidade ou mesmo uma inumanidade (VALADIER, 2003-2, p. $52(212))$.

Ammicht-Quinn também reflete sobre dignidade a partir da consideração com o mais fragilizado. Sua proposta é de uma teoria de consenso da dignidade que tenha como base o respeito à vulnerabilidade, portanto, uma imagem de ser humano que não se volte para a exclusão, mas sim para a inclusão. "A vulnerabilidade marca a um só tempo a necessidade de dignidade humana e sua possibilidade" (AMMICHT-QUINN, 2003b, p. 43 (203)). Portanto, apesar da dificuldade em compreender o termo "dignidade", ele se faz presente em documentos no campo da bioética, demonstrando a preocupação com a inclusão e o respeito pela pessoa vulnerável.

O conceito de pessoa, dessa forma, remete para a definição do termo, em primeiro lugar, mas também e principalmente para a maneira como relações são compreendidas, partindo da pergunta de fundo: como deve-se agir? $\mathrm{Na}$ bioética, são apresentados modelos através de escolas do pensamento bioético. Mesmo que as escolas destaquem aspectos diferentes da pessoa, sendo mesmo contrários, todas estão voltadas para o cuidado diante dos desafios da tecnologia médica e suas possibilidades de pesquisa. Concretamente, o embate se dá sobre o corpo.

\section{O corpo}

O conceito de pessoa cita a corporeidade sem aprofundar o tema. É o caso, por exemplo, de Boécio, quando afirma que a pessoa é uma substância individual de natureza racional. A materialidade corporal é determinante para a pessoa, pois é através daquela que essa passa a existir. Mesmo o corpo sendo elemento constituinte da pessoa, é somente a partir do século XX que passa a 
ser enfocado. Os estudos de Michel Foucault sobre o corpo, o poder e o saber descobrem o corpo como um lugar de escrita da história (FOUCAULT, 1998).

Em bioética, o corpo também é lugar de escrita, pois ao debater o conceito de pessoa, está-se também perguntando quem é a pessoa em sua materialidade corporal e quais são as possibilidades e limites de cuidado do corpo humano, que é a própria pessoa. Nesse momento, pessoa e corpo são uma só substância. A preocupação com a pessoa é a preocupação sobre a ação em relação ao corpo e o que dele é feito.

Como afirma Lepargneur em suas reflexões sobre bioética, pessoa "é o indivíduo consciente, dotado de corpo, razão e vontade, autônomo e responsável" (LEPARGNEUR, 1996, p. 44). O corpo aparece como um dos elementos constituintes da pessoa e é sobre ele que se escreve a história da bioética. São as possibilidades concretas de cuidado médico-tecnológicos que permitirão uma vida com mais dignidade, autonomia e responsabilidade. $\mathrm{O}$ debate em torno da dignidade e autonomia sobre o embrião, por exemplo, referese às possibilidades de utilização da materialidade corporal.

A relação entre a materialidade humana e o conceito de pessoa ocorre sob dois aspectos. Por um lado, a tecnologia médica desenvolveu novas possibilidades de tratamento e cuidado para o corpo. É o caso, por exemplo, do transplante de órgãos. Essa recente possibilidade de cuidado propicia um novo olhar sobre o corpo e, consequentemente, sobre a pessoa. Então, é a prática médico-tecnológica que orienta a discussão sobre o conceito de pessoa.

Por outro lado, o conceito de pessoa coloca limites na pesquisa médico-tecnológica através do debate sobre a dignidade humana. É o que registram as declarações dos direitos humanos e demais convenções de bioética, por exemplo. A pergunta de fundo é: as inúmeras possibilidades de investigação médico-tecnológicas são lícitas? Sob essa perspectiva, a filosofia e a teologia relacionam-se com a pesquisa médico-tecnológica. O resultado até o momento é uma situação de impasse sobre as possibilidades de pesquisa e investigação do corpo humano com fins de alcançar a saúde perfeita.

Peter Kunzmann (2005) participa da discussão enfocando a situação de empate. O filósofo afirma que o debate sobre o conceito de pessoa encontrase em uma situação de Patt (empate) como no jogo de xadrez. Isso ocorre porque o debate divide-se basicamente em dois grupos. Primeiro, o grupo que defende conceitos a partir da palavra "dignidade". Segundo, o grupo que defende 
a liberdade da arte e da imagem, cujo exemplo máximo encontra-se na exposição de arte Körperwelten ("Mundos Corpóreos").

A expressão artística tem utilizado o desenvolvimento tecnológico para se apropriar do corpo. A medicina tem pesquisado para dominar os males do corpo. O direito especifica os limites e possibilidades da medicina e suas pesquisas tecnológicas para o corpo humano em diferentes situações e idades. A lei de transplantes de órgãos e tecidos é a que mais aborda a questão do corpo em termos médicos. Outro exemplo é o debate sobre a pesquisa com embriões.

Cada país que busca aprimorar seus conhecimentos nessa área necessita de respaldo legal para tanto. Então, a legislação não deve apenas permitir ou não a pesquisa com embriões, mas deve também especificar que embriões em termos de tempo de vida e origem poderão ser utilizados nas pesquisas. Portanto, a discussão sobre a pessoa está diretamente relacionada com o que é feito do corpo, para o corpo, com o corpo, independentemente do tempo de vida envolvido na pesquisa.

1 Mundos Corpóreos é uma exposição do paleontologista alemão Günther von Hagen que foi exibida em vários países, tendo sido inaugurada em 1997. A exposição chamou muita atenção e é citada por vários autores devido ao material e à técnica utilizada pelo artista. Von Hagen preparou cadáveres, tornando-os plásticos, e assim foram exibidos ao público. Outros artistas têm utilizado seus próprio corpos para a expressão artística que utiliza novas tecnologias midiáticas de exposição. É a época do corpo biocibernético na sociedade pós-humana. Lúcia Santaella conceitua corpo biocibernético como "as artes que tomam como foco e material de criação as transformações por que o corpo e, com ele, os equipamentos sensório-perceptivos, a mente, a consciência e a sensibilidade do ser humano vêm passando como fruto de suas simbioses com as tecnologias" (SANTAELLA, 2003, p. 271). Essa autora apresenta uma ampla relação dos artistas que expressam sua arte através do próprio corpo utilizando novas tecnologias. É o exemplo de artistas que se penduram no teto, atravessando a pele com ganchos, ou que expõem imagens internas e externas de seu corpo em movimento, juntamente com os sons produzidos por ele, em salas pequenas e circulares (SANTAELLA, 2003, p. 286). Há exemplos menos chocantes, como, por exemplo, o projeto GFP Bunny, que modificou geneticamente uma coelha, Alba, através da aplicação de um gene que a tornou fluorescente - produz cor verde a qualquer emissão de luz azul (SANTAELLA, 2003, p. 299). Percebe-se que a expressão artística tem utilizado o desenvolvimento tecnológico para se apropriar do corpo. E, de acordo com Santaella, os artistas têm tomado a dianteira para descobrir a forma atual do corpo humano de uma maneira que ainda é invisível aos olhos da maioria das pessoas. Parece, segundo a autora, que a tarefa dos artistas é de anunciar uma nova antropomorfia (SANTAELLA, 2003, p. 271-299).

Rev. Pistis Prax., Teol. Pastor., Curitiba, v. 2, n. 1, p. 77-95, jan./jun. 2010 
BERGESCH, K.

Dessa maneira, o debate sobre o conceito de pessoa em bioética deve enfocar também a materialidade humana. Ao refletir sobre autonomia, justiça, virtudes etc, a bioética volta-se para uma ação sobre a materialidade humana. É o momento de sua apropriação, de seu conhecimento em termos de limites e desejos. Não mais apenas como nos falava Foucault: corpos dóceis, disciplinados e maleáveis, corpos voltados para a estética do momento, corpos belos. Mas é a percepção do corpo a partir dos avanços da biomedicina e das possíveis transformações do ser humano.

Nessa perspectiva, a pessoa não é compreendida apenas como corpo (objeto), e sim como uma só substância (fenômeno). A separação entre corpo e substância, aqui, segue a diferenciação existente na língua alemã entre körper e leib (SCHNEIDER-HARPPRECH, 2005, p. 209). Körper é o corpo que tenho, enquanto leib é o corpo que sou. Portanto, a pesquisa com embriões envolve tanto o leib quanto o körper.

\section{A relação corpo-alma na Teologia e no Aconselhamento Pastoral}

O Aconselhamento Pastoral compreende, hoje, que acompanhar uma pessoa em situação de crise, seja por motivos emocionais ou de doença, não significa apenas atender à sua alma, mas sim, à sua integralidade. O que muda é a perspectiva do acompanhamento. De acordo com Schneider-Harpprecht (2005), a Teologia e, por consequência, o Aconselhamento Pastoral tradicionalmente realizavam uma separação dualista na compreensão da pessoa, segundo a qual o corpo era menosprezado e a alma, valorizada. Nessa compreensão, o corpo era visto como o lugar do pecado, dos desejos, enfim, de tudo que desviava a alma da adoração divina.

A partir da segunda metade do século XX, essa compreensão dualista passa a ser questionada por várias áreas do saber, incluindo a reflexão teológica, de forma geral, e a Teologia Prática, de forma mais específica. Na Teologia Prática, corpo e corporeidade passam a receber atenção sob a perspectiva de uma realidade corporal. Isso significa que as reações do corpo e sua história passam a ser observadas e atendidas, não mais somente através da fala, mas também através da comunicação não verbal (STRECKER, 1999, p. 153).

Alguns teólogos, entre eles Dietrich Stollberg, passam a desenvolver uma teologia da encarnação orientada pelo corpo que valoriza a percepção da 
relação entre corpo e alma. Isso significa observar a linguagem corporal e a dimensão não verbal do encontro. Outros exemplos da reflexão teológica que relacionam corpo e alma são o bibliodrama e o psicodrama. A partir dessa relação, também a pessoa passa a perceber a relação entre corpo e alma, apropriando-se do seu corpo.

A Teologia e o Aconselhamento Feminista exercem um grande impulso em direção a uma nova compreensão teológica voltada para as mulheres, a partir do enfoque físico. A sexualidade e o corpo da mulher são vistos em uma nova perspectiva, opondo-se a uma tradição longa que sempre identificou o corpo da mulher com o mal e o pecado. Os textos bíblicos do Novo Testamento que relatam o encontro de Jesus com pessoas em diversas situações onde ocorrem diálogos e curas tornaram-se modelos para a reflexão teológica sob a ótica corporal. Uma expoente da Teologia Feminista é Elizabeth Moltmann-Wendel (SCHNEIDER-HARPPRECHT, 2005, p. 214).

Michael Klessmann (1997) observa que não há um só modelo de corpo. Por isso, a Teologia Prática não quer propor uma forma ou modelo, mas trabalha com a ideia da pluralidade de corpos e, consequentemente, conceitos e imagens que geram mundos interiores ricos e variados. Klessmann esclarece, a partir de estudos da neurologia, que cada indivíduo, ao longo de seu desenvolvimento, constrói sua própria imagem ou modelo corporal. Grande influência sobre essa construção são as relações familiares, principalmente entre mãe e filho, e o meio cultural (relações entre trabalho e liberdade, acompanhamento e cuidado de doentes, etc).

Apesar de todas as possibilidades de compreensão e construção da imagem física, Klessmann afirma que, ao longo da história, foram formados dois conceitos extremos e antagônicos. Por um lado, o corpo é depreciado e desvalorizado em favor de algo mais elevado, a alma imortal. Por outro, há uma supervalorização do corpo como único e essencial. A formação em um desses conceitos coletivos acarreta respectivamente uma série de consequências referentes à percepção da materialidade humana, das relações físicas entre seres humanos e do significado da vida.

Dessa forma, refletir sobre o corpo tanto como körper quanto como leib torna-se um desafio para o fazer teológico prático, tanto no acompanhamento de pessoas em sofrimento, quanto na reflexão sobre questões relacionadas ao início e ao fim da vida. Assim sendo, Klessmann busca um novo conceito de corpo para o Aconselhamento Pastoral, segundo o qual não 
se deve "compreender corporeidade e sexualidade como dimensões de vida divinas eo ipso, mas - no contexto de sua limitação e de sua condição fragmentária -, também como um espaço de possibilidade para experiências religiosas específicas"2 (KLESSMANN, 1997, p. 90).

\section{A multiplicidade de conceitos}

O corpo torna-se um lugar de escrita da história, que registra a experiência existencial, religiosa e de saúde. A tecnologia médica deseja construir um corpo saudável e perfeito. Essa busca significa, na pesquisa com embriões, a utilização da corporeidade humana como objeto. Justifica-se. Justifica-se! Eis a dúvida. O debate não se restringe apenas à busca por uma resposta positiva ou negativa para a pesquisa com embriões. Mas ele se volta também e principalmente para a compreensão que a sociedade possui sobre a própria humanidade na definição do conceito de pessoa.

Por isso, todos são convidados ao debate: cientistas, acadêmicos e população de forma geral, pois essa é uma questão que atinge a todos. Como lembra Kunzmann (2005), o debate oportuniza três possibilidades de encontro: primeiramente, o encontro de especialistas de várias áreas que possuem concepções diferentes, tanto em suas áreas de pesquisa e trabalho, quanto entre áreas diferentes; segundo, o encontro entre especialistas e leigos; terceiro, o encontro entre especialistas e leigos que participam diretamente do debate, e observações de leigos e especialistas que não participam diretamente do debate.

Ao formar conceitos, os elementos da liberdade, do acaso e das emoções estão presentes, marcando a formação individual. De acordo com Kunzmann (2005), a opção que as pessoas fazem por um conceito está diretamente relacionada com escolhas prévias que, por sua vez, são influenciadas por fatores psicológicos, do acaso e da liberdade. Por tudo isso é possível afirmar que seres humanos não são robôs inteligentes.

A partir desse quadro, o filósofo propõe que a pessoa deva ser compreendida na complexidade dos elementos que a formam. Isso significa que

2 No original alemão: "Leiblichkeit und Sexualität nicht als eo ipso widergöttliche Lebensdimensionen zu verstehen, sondern - im Zuzammenhang mit ihrer Begrenztheit und Fragmenthaftigkeit - auch als Möglichkeitsraum für spezifisch relisiöse Erfahrungen”.

Rev. Pistis Prax., Teol. Pastor., Curitiba, v. 2, n. 1, p. 77-95, jan./jun. 2010 
não há um conceito soberano sobre pessoa. Mas que, no contexto histórico de hoje, não deve haver uma substituição da razão pela intuição. O conceito de pessoa deve ser compreendido como conceitos de pessoa, considerando, portanto, a multiplicidade de áreas de estudo envolvidas no tema. A proposta não visa a uma hierarquia nessa compreensão, mas a uma cooperação no diálogo e compreensão sobre o conceito.

Zaborowski (2003) interpreta esse debate atual como um momento de crise. Em sintonia com Kunzmann, reconhece a multiplicidade de conceitos característicos dessa época. A reflexão de Zaborowski sobre pessoa não se volta para a procura de um conceito que se sobreponha a outros, mas em suas implicações práticas e morais. Por exemplo, a pesquisa com embriões possibilita a determinação da pessoa através de transformações médico-tecnológicas. Diante desse fato, a liberdade e a transcendência do indivíduo ficam comprometidas.

Ao modificar a materialidade humana, modifica-se a pessoa, portanto a compreensão da mesma. Dessa forma, as características do corpo passam a determinar a pessoa e suas relações. Segundo Zaborowski (2003), a manipulação genética coloca o indivíduo entre "algo" e "alguém”. Através dessa constatação o autor não deseja colocar-se contra a pesquisa com embriões, mas pretende chamar a atenção para as implicações morais e práticas frente ao conceito de pessoa. $\mathrm{O}$ autor propõe como limite para a transformação da corporeidade humana o respeito pela liberdade e a transcendência (ser humano como criatura de Deus).

\section{CONSIDERAÇÕES FINAIS}

Seguindo a reflexão de Kunzmann (2005), a dificuldade que se encontra no debate bioético atual sobre o conceito de pessoa surge da multiplicidade de conceitos oriundos principalmente na segunda metade do século XX. Essa multiplicidade não deve ser necessariamente interpretada de modo negativo. No entanto, ela dirige para uma situação de empate no momento de estabelecer conceitos e tomar decisões, pois, como afirma Zaborowski (2003), pessoa não é apenas um conceito que se desenvolve historicamente, mas ele traz consigo implicações morais que resultam em um conhecimento prático.

Dessa forma, definir o início da vida torna-se uma questão central. Não porque a vida tenha um ponto inicial, mas porque o ser humano precisa dessa definição para sentir-se seguro a fim de encontrar respostas que sirvam 
de ancoradouro para sua fragilidade e igualmente para possuir o respaldo legal e social em novas investigações científicas. Não somente pelo conhecimento, mas também para que a hegemonia de cada país possa ser mantida e, assim, garantir a liberdade e a autonomia de seus cidadãos.

Encontrar uma solução para o impasse diante da pesquisa com embriões e o conceito de pessoa não é tarefa fácil. Mas é extremamente importante. Por isso, a interdisciplinaridade torna-se fundamental. É somente através do diálogo que será possível compreender a imagem de corpo e ser humano que possuímos e as características pertencentes a esse conceito que necessitam de maior visibilidade.

\section{REFERÊNCIAS}

AMMICHT-QUINN, R.; JUNKER-KENNY, M.; TAMEZ, E. Editorial. In: AMMICHTQUINN, R.; JUNKER-KENNY, M.; TAMEZ, E. O discurso da dignidade humana. Concilium, v. 2, n. 300, p. 5(165)-8(168), 2003a.

AMMICHT-QUINN, R. Quem possui dignidade intocável? O ser humano, a máquina e a dignidade. In: AMMICHT-QUINN, R.; JUNKER-KENNY, M.; TAMEZ, E. O discurso da dignidade humana. Concilium, v. 2, n. 300, p. 31(191)-44(204), 2003 b.

CLOTET, J. Bioética: uma aproximação. Porto Alegre: EDIPUCRS, 2003.

DÜWELL, M. Utilitarismus und bioethik: das Beispiel von Peter Singers Praktischer Ethik. In: DÜWELL, M.; STEIGLEDER, K. Bioethik: eine Eiführung. Frankfurt am Main: Suhrkamp, 2003. p. 57-71.

FOUCAULT, M. Vigiar e punir: nascimento da prisão. 17. ed. Petrópolis: Vozes, 1998.

GOLDIM, J. R. Início da vida de uma pessoa humana. Disponível em: $<$ www.bioetica.ufrgs.br/inivida.htm>. Acesso em: 22 jul. 2009a.

Quando a vida começa? Disponível em: <www.bioetica.ufrgs.br>. Acesso em: 22 jul. 2009b.

KLESSMANN, M. Zur ethik des leibes: am Beispiel des Körperschemas. In: KLESSMANN, M.; LIEBAU, I. Leiblichkeit ist das ende der werke gottes: Körper, Leib, praktische theologie. Göttingen: Vandenhoeck und Ruprecht, 1997. p. 80-90. 
KUNZMANN, P. Person: die entscheidende instanz in bioethischen Debatten? In: BUSCH, R. J. FORUMTTN. Munique: Herbert UTZ, 2005. v. 13. p. 17-32.

LEPARGNEUR, H. Bioética, novo conceito: a caminho do consenso. São Paulo: Loyola, 1996.

SANTAELLA, L. Culturas e artes do pós-humano: da cultura das mídias à cibernética. São Paulo: Paulus, 2003.

SCHNEIDER-HARPPRECHT, C. Leib-Sorge? Die Wiederentdekung des Leibes in der Seelsorge. In: SCHNEIDER-HARPPRECHT, C.; ALLWINN, S. (Hg.). Psychosoziale dienste und seelsorge im krankenhaus: eine neue Perspektive der Alltagsethik. Göttingen: Vandenhoeck \& Ruprecht, 2005. p. 202-222.

SINGER, P. O que há de errado em matar? In: SINGER, P. Vida ética: os melhores ensaios do mais polêmico filósofo da atualidade. Rio de Janeiro: Ediouro, 2002a, p. 161-185.

Ética prática. São Paulo: Martins Fontes, 2002b.

STRECKER, J. Körperorientierte und kreative methoden in der Seelsorge. In: POHLPATALONG, U.; MUCHLINSKY, F. Seelsorge im plural: perspektiven für ein neues Jahrhundert. Hamburg: E. B. Verlag, 1999. p. 153-166.

VALADIER, P. A pessoa em sua dignidade. In: AMMICHT-QUINN, R.; JUNKERKENNY, M.; TAMEZ, E. O discurso da dignidade humana. Concilium, v. 2, n. 300, p. 45(205)-53(213), 2003.

VERSPIEREN, P. A dignidade nos debates políticos e bioéticos. In: AMMICHTQUINN, R.; JUNKER-KENNY, M.; TAMEZ, E. O discurso da dignidade humana. Concilium, v. 2, n. 300, p. 9(169)-19(179), 2003.

ZABOROWSKI, H. Wie machbar ist der Mensch? Die Würde der Person und die Grenzen der Machbarkeit. In: ZABOROWSKI, H. (Org.). Wie machbar ist der Mensch?: eine philosophische orientierung. Mainz: Matthias-Grünewald, 2003. p. 9-25.

Recebido: 15/10/2009

Received: 10/15/2009

Aprovado: 30/10/2009

Approved: 10/30/2009 